\title{
VISUALIZAÇÃO RADIOLÓGICA INTRAOPERATÓRIA EM CIRURGIAS DA REGIÃO CERVICOTORÁCICA. NOTA TÉCNICA
}

\author{
INTRAOPERATIVE RADIOLOGICAL VISUALIZATION IN CERVICOTHORACIC \\ SURGERY. TECHNICAL NOTE \\ VISUALIZACIÓN RADIOLÓGICA INTRAOPERATORIA EN CIRUGÍA DE LA REGIÓN \\ CERVICOTORÁCICA. NOTA TÉCNICA
}

Andrei Fernandes Joaquim¹, Enrico Ghizoni ${ }^{1}$, Marcelo Luis Mudo², Helder Tedeschi ${ }^{3}$

\begin{abstract}
RESUMO
Relatamos nota técnica de posicionamento do paciente para melhor visualização radiológica intraoperatória em cirurgias da região cervicotorácica.
\end{abstract}

Descritores: Vértebras cervicais; Vértebras torácicas; Fluoroscopia; Posicionamento do paciente.

ABSTRACT
We report a technical note on patient positioning to obtain a better intraoperative radiological view in cervicothoracic region surgeries.

Keywords: Cervical vertebrae; Thoracic vertebrae; Fluoroscopy; Patient positioning.

RESUMEN

Relatamos nota técnica sobre el posicionamiento quirúrgico para mejor visualización radiológica intraoperatoria en las cirugías de la región cervicotorácica.

Descriptores: Vértebras cervicales; Vértebras torácicas; Fluoroscopía; Posicionamiento del paciente.

INTRODUÇÃO

A junção cérvico-torácica compreende a região localizada entre a sexta vértebra cervical e a terceira vértebra torácica ${ }^{1}$. Constitui-se em uma região de transição entre a lordose cervical e a cifose torácica. Lesões nesta área de diferentes naturezas (neoplásicas, traumáticas, inflamatórias, etc) podem resultar em instabilidade com necessidade de tratamento cirúrgico para estabilização.

Acessos anteriores são utilizados como alternativa, tanto para estabilização quanto para descompressão da região. Contudo, a via posterior é direta e familiar aos cirurgiões de coluna, podendo ser extendida caudal ou cranialmente, além de fornecer inúmeros pontos de fixação². Seguindo estes princípios, muitas técnicas cirúrgicas foram descritas para estabilizar a região. A escolha entre as mesmas depende da experiência do cirurgião, anatomia do paciente e características da doença que resultou na instabilidade. Fixação com parafusos pediculares constitui-se em técnica altamente efetiva para estabilização da coluna, principalmente na região cérvico-torácica ${ }^{3}$. $\mathrm{O}$ uso desta modalidade de fixação oferece estabilização imediata, porém não é isenta de riscos, como violação do canal, lesão neurológica (mais de $80 \%$ do canal vertebral é preenchido por tecido neural nesta região) e lesão vascular ${ }^{2}$. Embora técnicas de instrumentação sem auxílio de radioscopia (free hand techniques) são descritas, a utilização de radioscopia intra-operatória constitui-se em um método auxiliar importante que permite a checagem da correta posição do instrumental, não sendo dispensável nem mesmo em mãos experientes. Infelizmente, a região cérvico-torácica é pobremente visualizada durante o ato operátorio. A visão lateral é prejudicada pelas articulações gleno-umerais, bem como costelas e caixa torácica que se sobrepõe em aquisições de imagem no plano coronal. Em contra partida, a visão antero-posterior é também ruim, devido a artefatos metálicos do fixador de crânio utilizado para o adequado alinhamento da coluna.
Contudo, o posicionamento adequado, fundamental para qualquer procedimento cirúrgico, permite a visualização radiológica em incidência antero-posterior da coluna cérvico-torácica, permitindo ao cirurgião a visualização dos pedículos, platôs vertebrais e do canal, dando mais segurança ao procedimento ${ }^{4}$.

\section{NOTA TÉCNICA}

Após anestesia geral, realizamos a fixação do crânio em três pontos, com o paciente ainda em decúbito dorsal. Com o uso de colar cervical, o paciente é colocado em decúbito ventral, certificando-se que o mesmo está com a coluna corretamente alinhada, com o olhar horizontal a posição de seu corpo. Devido aos artefatos metálicos, colocamos o fixador de crânio em uma posição mais anterior do que a usual, com o paciente posicionado mais caudalmente em relação a mesa cirúrgica. O ápice da cabeça é alinhado com a borda cranial da mesa (em situações convencionais, os ombros do paciente são colocados na borda cranial da mesa, enquanto que a cabeça fica no plano do fixador, impedindo a realização de radioscopia antero-posterior). Desta forma, o sistema de fixação fica localizado anteriormente a região cérvico-torácica, não interferindo na imagem radiográfica. Tal manobra permite a entrada do aparelho de fluoroscopia livremente, permitindo a checagem do posicionamento dos parafusos, bem como auxiliando na localização dos pedículos.

Todos os pacientes que requerem cirurgia nesta região são posicionados desta maneira por nossa equipe (Figuras 1 a 4).

\section{CONCLUSÕES}

Esta técnica de posicionamento permite a utilização de fluoroscopia antero-posterior na região cérvico-torácica e facilita a correta colocação de parafusos pediculares sem violação do canal.

1. Neurocirurgião Assistente, Disciplina de Neurocirurgia da Universidade Estadual de Campinas (UNICAMP) - Campinas, SP, Brasil.

2. Coordenador do Serviço de Neurocirurgia do Hospital Regional de Sorocaba, Sorocaba, SP, Brasil.

3. Professor Assistente Doutor, Chefe da Disciplina de Neurocirurgia da Universidade Estadual de Campinas (UNICAMP) - Campinas, São Paulo-SP, Brasil. 


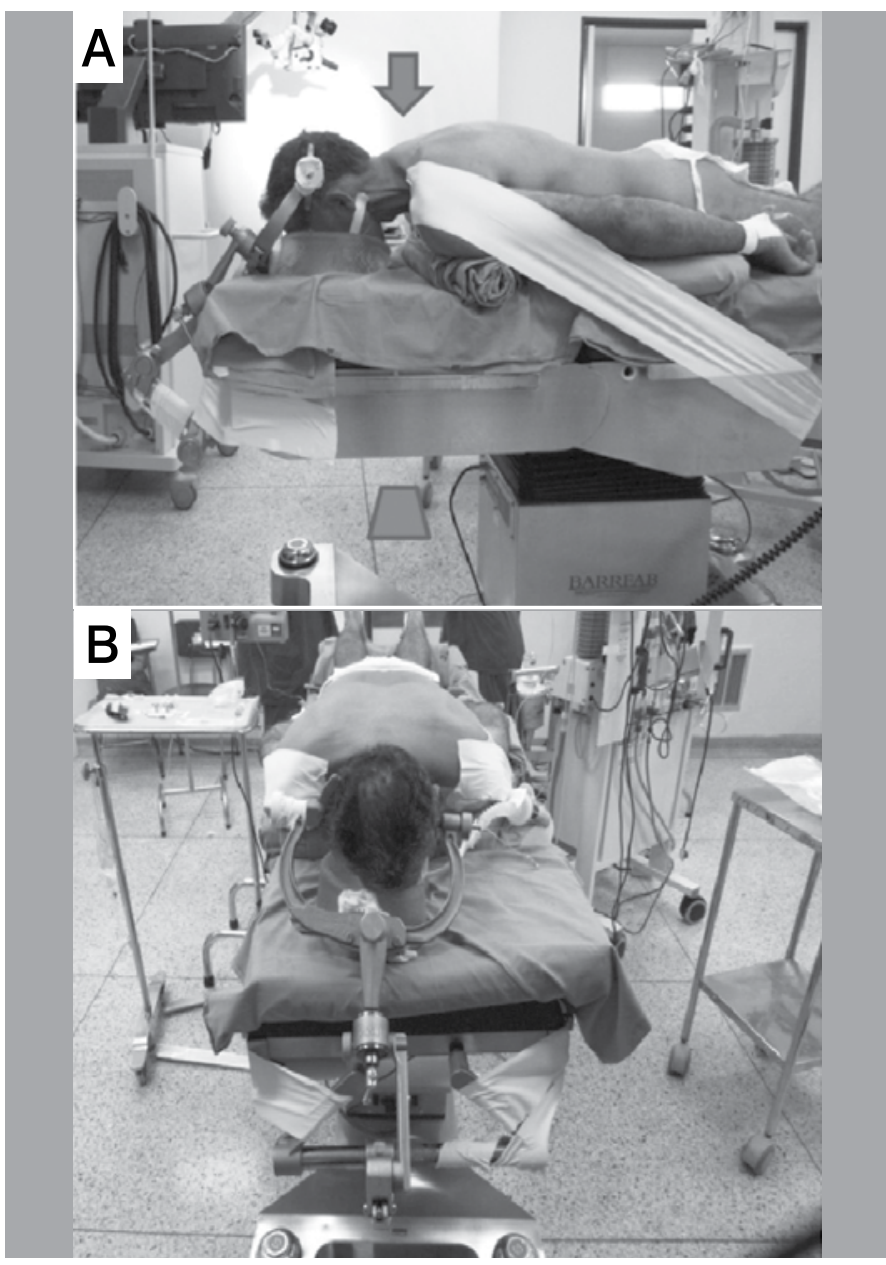

Figura 1. (A) Visualização lateral do paciente. Nota-se a colocação da crânio mais caudalmente a mesa, com o vértex da cabeça no limite da mesa cirúrgica. O fixador de crânio é direcionado para trás. As setas de cor azul ilustram o local de entrada do aparelho de fluoroscopia para realização de imagem sem a interposição do fixador de crânio. (B) Vista anterior do paciente posicionado.

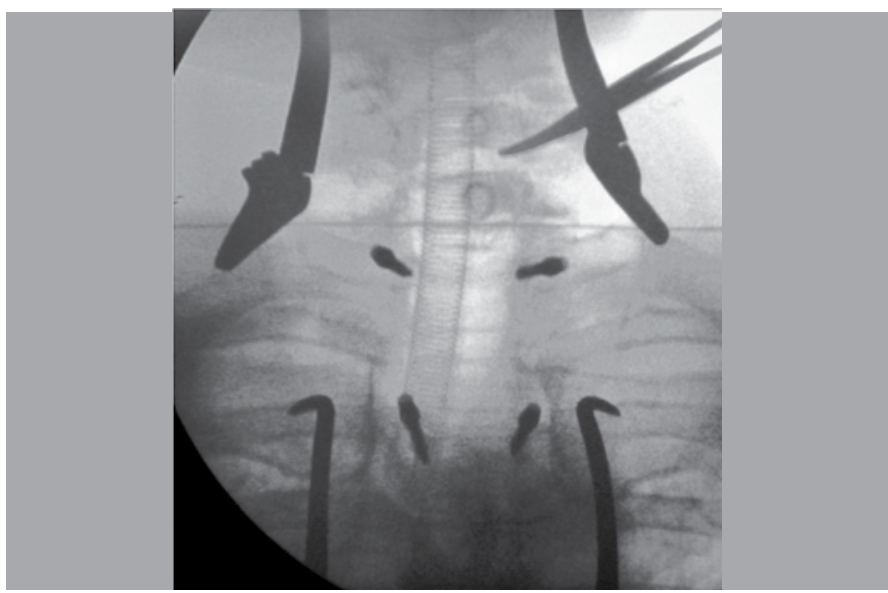

Figura 2. Visualização intraoperatória de radiografia da junção cérvico-torácica. Parafusos em pedículos em T1-3 podem ser visualizados.

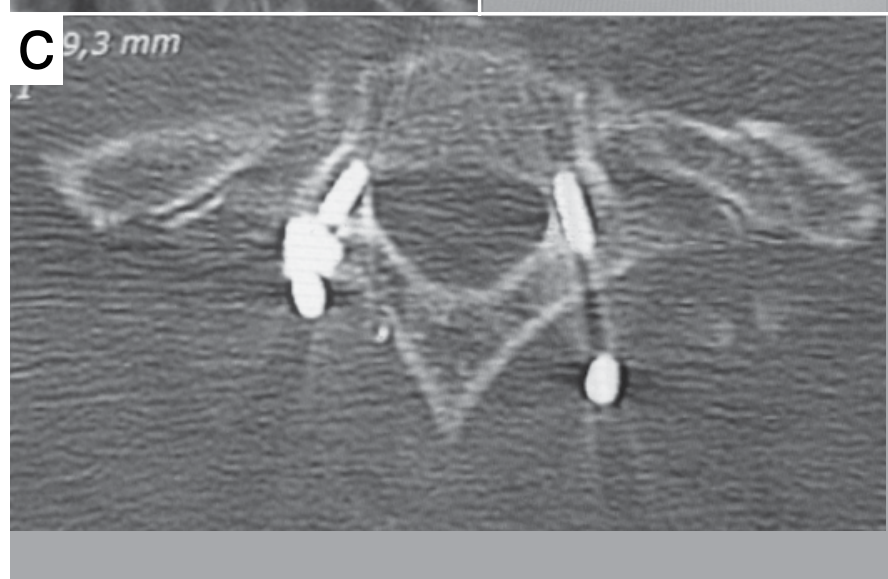

Figura 3. (A e B) Fixação C6-7 de lesão traumática em distração. A paciente foi submetida a fixação posterior de massa lateral em $\mathrm{C} 5$ e 6 e pedicular em $\mathrm{C} 7 \mathrm{e}$ $\mathrm{T} 1$ usando posicionamento acima descrito. (C) nota-se o correto posicionamento dos parafusos pediculares.
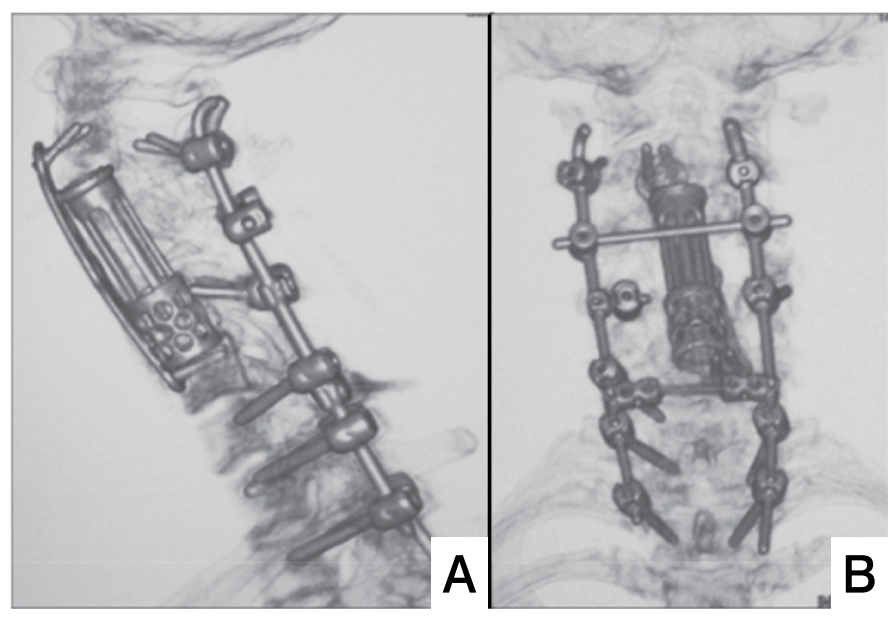

Figura 4. (A e B) Fixação complexa da região cérvico-torácica para tratamento de tumor ósseo primário. O posicionamento correto dos parafusos de $\mathrm{C} 7, \mathrm{~T} 1$ e T2 em posição radiológica antero-posterior é demonstrado na radiografia.

\section{REFERÊNCIAS}

1. Kurz LT, Pursel SE, Herkowitz HN. Modificado abordagem anterior para o junção cervical. Spine (Phila Pa 1976). 1996:16(Suppl10):S542-7.

2. Sapkas G, S Papadakis, Katonis P, Roidis N, Kontakis tratamento cirúrgico de G. lesões instáveis da junção cérvico. Eur Spine J. 1999;8(4):279-83.
3. An HS, Vaccaro A, Cotler JM, Lin S. Spinal disorders at the cervicothoracic junction. Spine (Phila Pa 1976). 1994;19(22):2557-64.

4. Mudo ML, Amantea AV, Cavalheiro S Joaquim AF. Visualização radiológica intraoperatória da região occipitocervical e coluna cervical superior: nota técnica. Coluna/Columna 2009:8(2):197-9. 